\title{
ANTIMICROBIAL USE, PRESCRIBING, AND RESISTANCE IN SELECTED TEN SELECTED DEVELOPING COUNTRIES: A BRIEF OVERVIEW
}

\author{
MAINUL HAQUE \\ Unit of Pharmacology, Faculty of Medicine and Defence Health, Universiti Pertahanan Nasional Malaysia (National Defence University of \\ Malaysia), Kem Sungai Besi, 57000 Kuala Lumpur, Malaysia. Email: runurono@gmail.com
}

Received: 28 April 2017, Revised and Accepted: 16 May 2017

\begin{abstract}
The widespread accessibility of antimicrobials transformed the path of olden times. Many infections beforehand not curable found treatment, for example, tuberculosis. Scientist, common people thought once that humankind has able conquered microbial diseases. Nonetheless, irrational and unnecessary use antimicrobials create resistant microbes throughout the universe. Moreover, the development new antimicrobials have slowed down, particularly for those diseases of developing countries who have very poor financial ability to pay the research overhead of the inventor. Thereafter, currently available antimicrobials antimicrobials are loosing their efficacy and spectrum everyday against resistant microbes. Subsequently, once those diseases were treatable with no antimicrobials or very low profile agents now need the higher form of antimicrobials even multiple agents. As such health care cost is increasing every day which is beyond the economic ability of common people of anywhere of the world. All these 10 developing countries very frequently were observed that overuse and irrational use of antimicrobials. Researchers of these developing countries opined that answer remains in continuing medical education for all health-related stakeholders and appropriate policy to stop irrational prescribing, and promote prudent and rational prescribing and use of medicine, including antimicrobials.
\end{abstract}

Keywords: Antimicrobial Use, Prescribing, Resistance, Developing countries.

(c) 2017 The Authors. Published by Innovare Academic Sciences Pvt Ltd. This is an open access article under the CC BY license (http://creativecommons. org/licenses/by/4. 0/) DOI: http://dx.doi.org/10.22159/ajpcr.2017.v10i8.19468

\section{INTRODUCTION}

Antimicrobial drug resistance (AMDR) of common infecting pathogens is a developing international intimidate to auspicious aftermaths of management of common infections in both community and hospital set up [1-3]. Increasing microbial resistance to antimicrobials even for dayto-day used medication for common infection became a domineering public health apprehension [3]. AMDR increases morbidity and mortality and correspondingly increases a great elevation financial liability to family and community or country [4,5]. Health systems, especially of low-income countries which are already struggling with chronic underfunding and weak institutional structures are particularly hit by AMDR [6]. Antibacterial drug development speed has much reduced, to effectively address the problems posed by AMDR, among significant bacterial pathogens, have been reported by a number medical societies and research group [7-15]. The situation is so bad that two leaders of both side of Atlantic the president of the United States, Barack Obama and the Prime Minister of the United Kingdom, David Cameron, and furthermore, the World Health Organization (WHO), in 2014, promulgate to necessary body to formulate and develop new strategies to fight against AMDR [16].

Sir Alexander Fleming raised the apprehension concerning antibiotic overuse when he notified that the "public will demand [the drug and] ... then will begin an era ... of abuses" by 5 years of use of penicillin and as early as 1945 [17-19]. The overuse of antibiotics evidently pushes the progression of resistance $[17,20]$. Epidemiological research studies have confirmed a straightforward correlation among antibiotic consumption and the development and propagation of resistant bacteria strains [21]. The principal factors are irrational antibiotic prescribing (over, unnecessary [such as for viral infection] and incorrect prescribing [30-50\% of cases]), wrong indication, wrong choice of medicine, wrong duration of therapy, and incomplete treatments and self-medication as well as inadequate infection control measures, especially in surgery and gynecological ward of any hospital to prevent spread of resistant bacteria both in the community and the hospital $[17,22,23]$. Furthermore, several studies reported that $30-60 \%$ of the antibiotics prescribed in intensive care units (ICUs) of modern countries such as the USA, the Netherland, and Australia, have been found to be superfluous, incorrect, or suboptimal [22,24-27]. The prescribing skill, attitude, and practice of medical doctors shows a fundamental play the lead role in the consumption of antimicrobials and is a prospective means for regulating and put away AMDR [6,28]. "Prescribing faults and prescription errors" are most important difficulties amid medication errors and very frequently observed in general practice and in the hospital [29]. "Rational prescriptions and use of medicines are governed by different aspects, such as lifestyles and habits, the culture of medicine use, the knowledge and culture of health care personnel and regulatory organizations' supervision and policies" [30]. Factors that in fact control irrational prescribing can be divided into 4 general categories: "scientific knowledge, patient-physician relationship, availability of suitable medicine alternatives, and function of inspectoral organization" [30]. The WHO also recommends that the accessibility of impartial evidence considering antibiotic is a precondition for rational antibiotic utilization and prescribing [4]. Moreover, medical students very often opined that clinical pharmacology was incompetently and ineffectively provided during their clinical clerkship period [31-34]. In addition, "prescribing is one of the biggest steps up from being a student to practicing as a doctor" [34] and habitually they learn prescribing by copying their seniors. Although, the WHO and several research studies have advocated the concept P-drug long before for improving prescribing quality, but incorporation to medical curriculum throughout was not very adequately practiced [35-40].

\section{METHODS}

The countries selected from Asia and conveniently. The articles were chosen on basis of browsing in Google and Google Scholar the Keywords: antibiotics, use, prescribing resistance, and the country. Article furthermore chosen on the basis free download and utilizing Universiti Pertahanan Nasional Malaysia (National Defence University of Malaysia, Kem Sungai Besi, 57000 Kuala Lumpur, Malaysia) link. Thereafter, many efforts have been given to cover as much article can be downloaded free and later utilized to develop the manuscript. 
Antibiotic use, prescribing, and resistance in different developing countries

\section{Kingdom of Saudi Arabia}

One recent study in Saudi Arab of 2015 reported that 92\% of the study participants thought that improper use of antimicrobials resulted in high escalation AMDR. Most of the physicians, nevertheless, were oblivious and uninformed of the precise nature resistance rates and patterns in their individual establishments. The same study also found that poor knowledge is the most important contributor to poor antimicrobial application and consumption. The study participants also opined that free access to antimicrobials in Saudi Arab and contemptible supervision quality regarding antibiotic use were other important determinants. Hence, this research highlights the burning necessity for carefully designed strategic policies to combat the knowledge loopholes and to develop the rational use of antimicrobials [41]. Another study conducted in Saudi Arab of 2016 revealed that $82 \%$ of respondents stated that AMDR is a global serious delinquent, and 78\% also believed that such resistance trouble equally exists in Saudi Arab. Research participants' attitudes regarding antimicrobials did not be at variance from corner to corner with their subjects or intensities of training. A good portion of study respondents thought that the amount of AMDR are almost equal in their hospitals as of other countries. Over $2 / 3$ of the study respondents could categorize the most common resistant organisms of their hospital or in the community [42]. Another study of Saudi Arab of 2015 assesses and clarifies about physicians' insights and awareness about antimicrobial observed that good knowledge and outlook of maximum study participants. General practitioners (GPs) give the impression to possess an imprecise acuity on problems concerning the choice of antimicrobials. The immense advantage of continuing education regarding antimicrobial use and prescribing were not effectively valued by all study clusters. Furthermore, there has been a disparity and inconsistency observed between the cohorts of the three study groups - GPs, resident physicians, and specialists. Hence, necessary educational interventions (EIs) were the need and measures can improve rational prescribing of antimicrobials [43].

\section{Republic of India}

One Indian study reported in 2016 that only 35.94\% of medical doctors perceive remarkably self-confident about themselves about the best use of antimicrobials and the main stream of study population brush up their choice with a high-ranking teammate about of correct the selection of antimicrobials both for in- and out-patient of their hospital. Researchers pessimistically noticed that $84.37 \%$ of doctors in this study had under no circumstances received teaching-learning on antibiotics as part of the educational accomplishments in the individual department during the past year and $87.5 \%$ had not taken part in any course-work on antimicrobials during the past year. Most of the study participants opined that some antibiotics accessible in their hospital are of poor quality and less effective while only $4.69 \%$ differed. More than $50 \%$ of physicians participated in the study make a clean breast about that they often struggle to select the accurate antimicrobials for clinical situations. Again, $43.75 \%$ of them while choosing right antimicrobials cogitate about the causative organism but rest $45.31 \%$ of think about on the availability of antimicrobials. Much of the study participants assumed that development of a local guideline would be more useful and promote more rational antibiotic use than the international one. Since of antibiotic possess diverse susceptibility pattern of microbes in different regions, but $10.94 \%$ recognize that guidelines are hurdle more than a help to clinical care, may be because guidelines create a boundary to some magnitude for the clinical judgment. Although a great majority of research participants approved that superfluous use of antibiotics impairs patients' health, on the other hand, a small group of $9 \%$ did not perceive similarly. Participation in EIs must be emphasized to promote rational antimicrobial use [44]. Almost all the study participants' interns told that virus is the contributory agent for common cold and cough. In addition, $87 \%$ and $78 \%$ of interns and residents, respectively, believed that antimicrobials are ineffective in such trivial illness. Nevertheless, $40 \%$ of residents replied that antimicrobials have a definite role in acute diarrhea which is in conflicting with evidencebased medicine, as most of diarrhea caused by a virus. Once again similarly, most of the interns have wrong insight that antibiotics were effective in a sore throat. It is good to know that all the study groups are aware that indiscriminate use of the antibiotic will lead to resistance and medicine microbes are often very difficult to treat. Virtually, all medical background study participants contemplate that AMDR as a national problem of India. Hence, only $15 \%$ and $25 \%$ of interns and residents replied that they will start antibiotics for flu for themselves. This is essentially replicates that majority of these medical doctors of India will not prescribe antibiotic irrationally which is an auspicious finding to combat antibiotic resistance. Furthermore, $85 \%$ and $72 \%$ of residents and interns sense that the use of antibiotics will not expedite the convalescence and improvement of the common cold. All the study groups opined that they will complete the whole course of antibiotics even their symptoms subsided. Furthermore, $77-88 \%$ of the residents and interns thought that not to change antibiotic before whole treatment schedule completed but will change to a new antibiotic dose schedule if failed to cure after completion of the course [45]. Another Indian study revealed that $79.27 \%$ of the respondents agreed that random and imprudent use of antibiotics will block the success of treatment, augment adverse effects, development of bacterial resistance, amplified hospital stay and an added burden of medical overheads not only to the patient but also for community/country. The same study also found that majority (96.38\%) of the participants believed agreed that AMDR was a domineering and a grave universal and national public health delinquent [46].

\section{The People's Republic of China}

Prescribing one antibiotic and multiple incompatible antibiotics in viral infection was noticed in the treatment of $97 \%$ and $37 \%$ were spotted, respectively. The far majority (63\%) patients with suspected bacterial infection received antibiotics, nonetheless with wrong choice, dose, duration, and formulation were detected. EIs and with high-quality training improves prescribing qualities toward the judicious use of antibiotics by enlightening their knowledge and attitude regarding antimicrobials [47]. It has been reported from rural China that medical doctors have high propensity to prescribe more expensive proprietary branded antibiotics, especially for insured patients to maximize their personal earnings and profits [48,49]. Coughs and diarrhea were regularly treated with antibiotics in China. Interestingly, antiviral medicines are also added in common cold. Several physicians trust that addition of antibiotic will enhance the recovery. Although they clearly know common cold is a viral disease and regularly self-limiting. The major cohort of physicians is acquainted with AMDR and its' problem to treat microbial diseases. Pharmaceutical industries often offer the very handsome amount of financial incentives to prescribe antibiotic and physician receives profit splitting with pharmaceutical companies. Again, a foremost portion of a hospital's revenue is generated antibiotic or any medicine sales. The national guideline in China regarding the practice of antibiotics prescribing is inadequate, incomplete, and not updated regularly [50]. In China, generalized linear regression analysis showed that clinicians who either worked in the internal medicine department, those particularly received and availed specialized training on antibiotic use and prescribing possess better knowledge level than those work in tertiary hospitals, secondary hospitals or primary health care facilities. Henceforth, Chinese medical doctors have inadequate knowledge regarding antimicrobials use, prescribing and resistance. Thereafter, like any other countries continuing medical education, especially regarding clinical pharmacology is effective to augment doctors' knowledge, attitude, and practice. Subsequently, added EIs is the only answer for advancement knowledge about antimicrobials, especially for clinicians employed in primary health care settings [51].

\section{Malaysia}

One Malaysian study in 2015 reported that most of the Malaysian GPs possess a reasonable level of knowledge about the management of upper respiratory tract infections (URTIs) nonetheless a minor fraction 
having an inadequate knowledge regarding URTIs and relevant rational prescribing [52]. Furthermore, $84.2 \%$ of studied GPs approved that furthermost URTIs are triggered by the virus. In addition, research participants GPs believe that antibiotic resistance is the major public health problem for their own country and globally [52]. Nevertheless, a statistically significant difference $(p=0.042)$ was observed among the responses to the statement "most URTIs are caused by viruses" and GPs years of practice [52]. Interestingly, GPs who appropriately responded were relatively younger group than those answered wrongly. Faulty responder had been practicing for more than 30 years. Promisingly, most studied GPs (78.4\%) informed that they did not prescribe antibiotics on demand by patients except medically required. Against such background of such positive findings, this research also found some disgraceful findings. On an average, $61.13 \%$ of research participants GPs possess erroneous knowledge on the consequence of antibiotic in treating URTIs [52]. A total of 6747 prescriptions were audited in Sarawak, Malaysia and stated that prescriptions for URTIs with antibiotics prescribed were $64.8 \%$ (95\% confidence interval [CI] $63.7 \%, 65.9 \%$ ] [53]. Tonsillitis and Pharyngitis cases were prescribed $97 \%$ and $95 \%$, respectively, with antibiotics by the prescribers of Sarawak. The Sarawak study finally concluded that there was a very high rate of irrational antibiotic prescribing for URTIs [53]. Another study reported that medicines prescribed by Malaysian GPs for common were cold syrup (25.5\%), antibiotics (18.5\%), antipyretic/analgesics $(14.8 \%)$, antihistamines $(13.9 \%)$, cough lozenges $(11.6 \%)$, combination of antihistamines and decongestants (9.7\%), Vitamin C (2.7\%), and other medications (3.7\%). In addition, it was also revealed that $80 \%$ of the GPs prescribed antibiotics and this was more predominant and significantly higher in the rural settings $(p=0.034)$ [54].

\section{The Democratic Socialist Republic of Sri Lanka}

One Sri Lankan study concluded that antibiotic prescribed practice for acute respiratory tract infections (ARTIs) was very often almost regular basis at Sri Lankan government hospitals. Physicians' of those hospitals claimed that "patient demands, imprecise diagnosis, and fear of bacterial superinfection, as well as structural factors such as high patient volume and short visit times" were the principal cause of antibiotic prescribing. EIs aiming for prescribers, patients, and the public, in conjunction with systematic changes, are immediately desirable to develop and progress the rational and evidence-based prescription of antibiotics in such scarce resource backgrounds [55].

\section{The Islamic Republic of Iran}

One Iranian study evaluating 1506 cases of under 5 years ARTIs patients revealed that $75.9 \%$ (1143) were referred to urban or rural health care centers. Antibiotics were prescribed 62.6\% (715) of ARTIs affected pediatric patients. Injection formulations were used for $13.1 \%$ (150) of patients. The frequency of receiving antibiotics and referral to health care centers were statistically significantly higher among urban pediatric cases than in rural cases $(66.0 \%$ versus $57.7 \% \mathrm{p}<0.05$; 43.4 versus $30.4 \% ; \mathrm{p}<0.001$ ), respectively [56]. In addition, referral to private hospitals and clinics were statistically significantly higher in city patients than from countryside ( 43.4 versus $30.4 \% ; \mathrm{p}<0.001$ ). Researchers' also reported that $90 \%$ of children need medical and health care for respiratory infections were of viral etiology and has no advantage and role of antibiotic [56]. Fundamental of whys and wherefores for overuse of antibiotics regardless of the scientific opposition are various and differ from place to place. The poor knowledge level leads to the delusion of both patients and physicians about the effectiveness of antibiotics is the principal cause of irrational use of antimicrobials medicines. Moreover, peer pressure for antibiotics and doctors do not want to lose their earning by displeasing their patients. Research also reported that poor professional skill of medical doctors to differentiate between bacterial from viral diseases often promote excessive antimicrobial prescribing. Furthermore, the poor professional skill of medical doctors generates more apprehensions and physicians exaggeratedly vigilant regarding patients from complications of the diseases, hence, prescribe antibiotics in viral infections to protect their practice and earnings [56]. It has been reported that Azar Hospital, Golestan University of Medical Sciences 69\% (220 cases of 318 admitted patients) had received antibiotics in internal, infectious disease, and surgical wards and ICUs [57]. Same study and several other studies conveyed that irrational prescription of medicine including antimicrobials possibly will result in poor health status and enormous financial impact for any community or country [57-61]. Antimicrobials alone took the share $30-50 \%$ of all prescribed medicine in quite a lot of countries [58,62]. Research Center, Shiraz, Iran reported in Editorial in the most prestigious medical journal the Lancet that "antibiotics are an important front-line instrument in the fight against various infectious diseases. However, they are often used irrationally - meaning that their misuse, and the subsequent development of antibiotic resistance, is an important health-care issue worldwide" [63]. Another research conducted in surgical units of 6 teaching hospitals affiliated with Shiraz University of Medical Sciences, Iran showed that virtually all surgical patients received minimum one antibiotic as prophylaxis for any infection. Even though, this imitates the surgical specialist doctors' cognizance about the value of antimicrobials to prevent and control surgical infections nevertheless this research results also demonstrated the overuse of antibiotics in Iran since in 98\% of all surgical measures antibiotics were prescribed antimicrobials without any scientific evidence of infection and pertinent necessity [64]. Finally, the study concluded the overuse and inappropriate of antibiotics along with poor hospital management not only increases financial overheads for the family and community or country but also promote and progress to develop resistant microorganism [64]. Another research to ascertain antibiotics use patterns in ICUs of 5 hospitals in Tehran disclosed that the use of antibiotics was higher than expected, nonetheless, antibiotics consumption style was not similar from other countries. Expensive antibiotics such as vancomycin and carbapenems were prescribed much more than actual need give increase to in extra cost for patients, hospital and health care system. Researchers also noticed in these hospitals that there were almost no existence drug policy plan and program, or protocols, guidelines, formulary books, lack of continued medical education, lack of pharmacologist, or clinical pharmacologist and finally, no dependable monitoring and evaluation program of antibiotic use. These factors affect negatively antibiotic utilization patterns in ICUs and hospitals and escalated microbial resistance toward medicine and increase financial burden. Therefore, this delinquent should be resolved by promoting rational use of antibiotics in these ICUs and hospitals through necessary EIs [65]. One more Iranian study regarding antibiotic use neurosurgical procedures found that inconsistencies about antibiotic selection, duration, and start time of prophylaxis were observed between current administration and the American Society of Health-System Pharmacists (ASHP) guideline. The cost of prophylactic antibiotics use for neurosurgical interventions was 14 times greater than what it would have cost to administer prophylactic antibiotics adhering to the ASHP guideline. This study concluded that there is an essential need of EIs to promote and progress of the rational use of antibiotic and other medicine to prevent and reduce morbidly and mortality due to irrational use antibiotic and other medicine [66]. A systematic review suggested that generally there was an increase in AMDR in throughout the Iran. Researchers suggested that the need for effective surveillance program to prevent AMDR [67].

\section{The Kingdom of Thailand}

Antibiotics are among the most commanding and imperative medicines. Antimicrobials can save lives when prescribed, dispensed, and taken correctly, but its' unnecessary and improper can be enormously injurious. Irrational use of antibiotics is particularly bad in Thailand, with 100 patients dying every day because overuse of antimicrobials generating AMDR, it is worse than all the European countries and many other parts of the planet. Antibiotic resistant microbial infections kill up to 38,000 Thai national annually. It has been claimed that over prescription and the prevalence of the drugs in food and the water supply generate resistant microbes. Drug System Monitoring Mechanism Development Centre reported that Thailand 
had a troublingly from top to bottom casualty rate due to AMDR, but the problem was concealed because the reason of death was generally registered as somewhat else [68]. Another study revealed that $80.9 \%$ were prescribed antibiotics empirically at the preliminary phase for treatment of nosocomial infections. Ceftazidime and imipenem/ cilastatin or meropenem were also frequently used inappropriately almost $26 \%$ of cases. The research results recommended that overuse of certain antibiotics continue to be an unresolved problem. Proper monitoring and stringent control of the use of antibiotics are indispensable to promote and advancement rational use of medicine [69]. Poor antibiotic prescribing has been reported that at least 27 years back from a study conducted in a University Hospital, Bangkok, Thailand. This study revealed that only $8.8 \%$ prescribing antimicrobials were completely based on science and rest $91.2 \%$ were irrational [70]. There was also noticed that tendency to prescribe of costly proprietary antibiotics, even cheaper and effective alternatives antimicrobials were available. Researchers calculated that the financial overhead increased around the US $\$ 40,000$ each year on the medical wards alone for wrong and necessary prescribing antibiotics [70]. Finally, the study concluded that antimicrobial use in a university teaching hospital in Bangkok, Thailand, echoes a form head to foot quantity of mismanagement both medicine and public money. Thereafter, the urgent necessity for rationalization of antimicrobial use through EIs [70]. Another study from Thailand focused on specialized training and education for antimicrobials reported that an EIs and antibiotic management program constituted an operative and cost-saving stratagem to enhance and improve antibiotic utilization in a tertiary care hospital in Thailand. There was a statistically $(p<0.001)$ significant reduction in the rate of antibiotic prescription, inappropriate antibiotic use, and sustained reduction in antibiotic use. Although considerable antibiotic misapplication persists in several areas that may be tough to control only through controlled access. Assessing and strengthening to ensure to follow local hospital and national guidelines through continued educational and advocacy program are of necessary [71]. Irrational antibiotic uses prompt and persuade to a variety of adverse outcomes which include superfluous revelation to antibiotics, insistent or ongoing infections, superinfection, and enhance overheads [72]. The incidence of irrational antibiotic use was $25 \%$ in a tertiary health care center, Thailand. Multivariate analysis both the surgery (adjusted odds ratio [OR], 2.0; 95\% CI, 1.1-3.6; $\mathrm{p}=0.02$ ) and obstetrics and gynecology (adjusted OR, 2.0; 95\% CI, 1.1-4.1; $\mathrm{p}=0.03$ ) unit revealed that were associated with irrational antibiotic use. However, discussion with an infectious diseases specialist before prescribing was found protective against irrational antibiotic use as adjusted OR has reduced (adjusted OR, 0.15; 95\% CI, 0.03-0.65; p=0.01) [73]. Another study from rural Thailand found that $82 \%$ of all outpatients with influenza-like sickness were prescribed antibiotics. Interestingly access to a prompt influenza test outcome was associated with a significant decrease $(73 \%$ versus $87 \%$, respectively, $\mathrm{p}=0.003$ ) in antibiotic prescription and promote rational prescribing. The study finally concluded that wide accessibility user-friendly rapid influenza testing and expanded physician continued education diminishes the irrational antibiotic use, promote prudent use, and progress patient care [74]

\section{The Republic of the Philippines}

Antibiotics therapy are largely advantageous in treating susceptible bacterial infections, but such useful properties are counterbalanced by widespread and extensive irrational consumption [75]. The major importance of misuse of antimicrobials is the rapid advent of AMDR [76-78] and its' consequent disease aftershock [74]. Irrational antibiotic use refers to inappropriate, imprudent and does not comply evidence-based medicine with respect to choosing the drug, dose, interval, duration in the light of appropriate clinical circumstances and/or financial contemplations [79]. The President of the Philippine Society of Microbiology and Infectious Diseases, told that in the Philippines $66 \%$ of antibiotics were sold without a prescription citing one reference $[80,81]$. Another study from the Philippine discovered that most the juvenile diseases are treated without accessing by a medical doctor. At least $50 \%$ of pediatric patients were consumed modern pharmaceuticals medicine both of over the counter (OTC) and prescription only without prior proper medical consultation. In the Philippines, symptomatic treatments were highly prevalent, especially of antidiarrheals and cough syrups. Moreover, all contraindicated antidiarrheals and around $50 \%$ of the anti-cough agents prescribed, utilized, and consumed in common pediatric diseases. The reason behind such irrational attitude was described that the medical doctors prescribe very often expensive proprietary medicine and harmful symptomatic treatment [82]. Globally, much of the antimicrobial medicines are retailed without a prescription or faux pas by healthcare professionals. In addition, non-prescription consumption of antimicrobial accounted for $19-100 \%$ outside of Northern Europe and North America. Non-prescription antimicrobials consumption raises several safety issues which include adverse drug reactions (ADRs) and concealing of primary reasons of infection. In many parts of the world, very often almost all antimicrobials are purchasable, OTC, without any graduate medical doctors' prescription, including antitubercular medicine. Antimicrobial-resistant microbes are common in peoples, societies, and countries with everyday non-prescription use [83].

\section{The Federal Democratic Republic of Nepal}

One study in Nepal in 2006 conducted at the Manipal Teaching Hospital, Pokhara, Nepal found that $12.1 \%$ prescription contain a different type of antimicrobials [84]. Again, at least $40 \%$ of medicine were from the Essential Drug list of Nepal. Hence, this small Himalayan country has achieved good progress in rational antibiotic prescribing. The same study also similarly uttered that irrational medicine prescribing and consumption often lead to a reduction in quality of drug therapy, increased the risk of ADRs, AMDR, etc., [84]. 2 years later another study in the same hospital reported that antimicrobials also accounted for $11.86 \%$ of the out-patient medication. It was also found that $37.09 \%$ and $31.06 \%$ of the medicines prescribed were from the Essential drug list of Nepal and WHO Essential drug list, respectively. A very high percentage (97.92\%) of the medicine was prescribed from the hospital drug list and $47.75 \%$ of the drugs were from the Nepalese National Formulary [85]. Both the studies reported almost identical findings. One more study conducted in a tertiary teaching hospital in 2013 reported that $75.6 \%$ of working doctors demanded that they had adequate knowledge about the new antibiotics and their usage, although only $38 \%$ had attended an official training session on the newer antibiotics last year. Again, most of the study participants (88.9-95.6\%) unquestionably opined to possess an acceptable level knowledge and to interpret about the laboratory studies related to infections. Nonetheless, about $84.4 \%$ were aware of the antibiotic policy in their hospitals. Almost all the study participant doctors (91-97.8\%) claimed that they advised and explained the necessity to complete the whole course of antibiotics even their symptoms subsided. Nevertheless, $56.6 \%$ opined that they took special attention in guiding their patients about the correct use of antibiotics. Most of the participants answered that they had prescribed both branded as well as generic antibiotics. Nonetheless, $66.7 \%$ of participants believed antibiotics were largely overused. Nearby $37.8 \%$ of the study participants preached that AMDR exists and a problem of their hospital. A good number of the participants (45-88.9\%) thought that they never overused antibiotics and always keep in their mind overall issue of resistance while prescribing antimicrobials. Moreover, 91\% of respondents thought that their antibiotic prescribing quality are up to the mark and just over (55.6\%) of half them discuss and consult with other colleagues while prescribing antimicrobials. About $97.8 \%$ either strongly agreed or agreed that a prudent use of antibiotics is advocated to improve current scenario of AMDR. Only $13.3 \%$ agreed that promotional activities of pharmaceutical industries had influenced and triggered high rate antibiotic prescriptions. Finally, this study concluded that rational use of medicine, especially antimicrobials are essential to control and prevent microbial resistance against antimicrobials and safeguard communities [86]. Another study conducted in primary health care settings in Western Nepal in 2012 reported that $57 \%$ of the total patients received at least 
one antibiotic per prescription [87]. The WHO acclaims that it could be as high as $15-25 \%$ of the prescription may contain antibiotic in those countries where infectious diseases are predominant and widespread [88]. Henceforth, authors concluded that overuse of antibiotics are widespread in most of the studied primary health care settings and increases the possibility of microbial resistance [87]. Another study examined 4231 prescriptions in a teaching hospital of Western Nepal reported that $28.3 \%$ contain antibiotics [89]. This is also higher than the WHO standard [87]. Therefore, authors concluded regarding antibiotic prescribing that result does not specify that the prescription pattern was irrational prescribing and dispensing [89]. One more study appraises prescription pattern, and rational prescribing in the eastern part of Nepal found that an antibiotic was prescribed in 364 patient encounters were $40.44 \%$. Although prescriber often used generic name $(45.18 \%$ [ $n=872])$ and from national essential drug list (76.11\% [ $n=1469])$. Researchers felt that polypharmacy, overuse of antimicrobials increases the possibilities of more ADRs and resistances to microbes. Finally, the study recommended EIs to rectify and promote rational prescribing [90]. Another study again assessed the prescribing patterns of antibiotics in the Internal Medicine ward of a teaching hospital in Western Nepal reported that the most commonly prescribed antibiotics were ampicillin, amoxicillin, metronidazole, ciprofloxacin, and benzylpenicillin. Of 687 patients studied, 203 (29.55\%) were prescribed antimicrobials. Patients who received antimicrobials $48.3 \%$ (98), 36.9\% (75), 11.3\% (23), 2.5\% (5), and 1\% (2) were prescribed 1, $2,3,4$, and 5 antibiotics patients, respectively. This study furthermore found that antibiotic resistance is a real threat to ensure treatment of infectious diseases in the Internal Medicine ward of Manipal Teaching Hospital, Nepal. Thereafter, researcher recommended for the formulation of hospital guideline of antibiotic use, stringent policy for implementation of the guideline, and an EIs program for doctors [91].

\section{The People's Republic of Bangladesh}

One research study regarding prescription antibiotics for outpatients in Bangladesh conducted in three cities reported that on an average 50\% contain antimicrobials. Males (61\%) were receiving antimicrobials $22 \%$ higher than female (39\%) patients. Although $83 \%$ of prescriptions contain no documentary evidence of laboratory or clinical test for prescribing antimicrobials. It was also found that multiple antibiotics were prescribed in $25.44 \%$ of prescriptions. Nevertheless, $61.78 \%$ of patients recovered from illness and $38.22 \%$ of patients did not follow properly doctors' advice. A total of 900 prescriptions were evaluated and found that cold and fever (34\%), infections (42\%), diarrhea (14\%), gonorrhea $(3.67 \%)$, and other diseases $(5.67 \%)$ were the principal reasons to prescribe antimicrobials. This research finally concluded that indiscriminate use of antimicrobials promotes rapid spread of microbial resistance to antimicrobials. The study also appealed to the Bangladeshi medical doctors and other health professionals to be more proficient and cautious when prescribing antibiotic in any settings. Government of Bangladesh should initiate appropriate policies to promote judicious and prudent use of antimicrobials and continued EIs need uphold for all stakeholders for antimicrobial use and prescribing [92]. Another study reported from Bangladesh that communicable, transmissible and contagious diseases are most important health difficulties necessitating everyday use of antimicrobials. These microbial diseases very often diagnosed and treated empirically. Respiratory tract infection, urinary tract infection, enteric fever, wound infection is regularly treated empirically. Since laboratory investigations to document microbial sensitivity and to choose medicine either not available or extremely expensive. Most alarming thing is many infectious diseases do not respond to conventional antimicrobial agents [93]. It has been reported in editorial that antibiotics are one of the utmost frequently prescribed medicines. Antimicrobials are life-saving, but it is equivocally life-threatening. Antimicrobials saves life certainly when prescribed rationally, but irrational prescribing cause more impairment than conserve. Globally, irrational use of antimicrobials is practiced leading to emergence of resistant microbes, increase ADRs, and financial overhead. Very urgent work plan is needed to avert the existing condition of increasing microbial resistance. The best solution till date is the rational use of antimicrobials. All health care authorities need to be highly vigilant to promote and ensure rational use in every tire of health care settings [94]. Another study reported that antibiotics prescribing rates was found high, especially among extreme age groups [95]. Researchers explained that these age groups are, particularly vulnerable to infective diseases [96]. Researchers also have a suspicion that for pediatric patient of 0-15 years' age peer pressure was a prime factor for very high rate $(34.34 \%)$ of antibiotic prescribing. Researchers also revealed care that common people exclusively caregivers of young children believe that antibiotic is a panacea [95]. Another survey among physician also reported that significantly more doctors prescribe antibiotics in suspected infections $(\mathrm{p}<0.0001)$. Slightly, more than $44 \%$ of doctors prescribe antibiotics in cold and fever. A significant portion (31.9\%, $\mathrm{p}<0.0001$ ) of doctors on no occasion obtain any opinion about the prescribed antibiotic. Researchers also found that non-compliance $(68.8 \%)$ is the central basis of AMDR in Bangladesh. A good number $(26.7 \%, p<0.0001)$ of patients had a predetermined idea there is no need to follow doctors' instruction. In addition, more than $50 \%$ of patients stop antimicrobials as soon as the symptoms start improving and reduced [97]. One more research studied prescribing trends in the outpatients of Sir Salimullah Medical College and Mitford Hospital, a tertiary care hospital, Dhaka Bangladesh. This research reported that there is an inclination headed for irrational prescribing, predominantly the over-prescribing of antibiotics and under-prescribing of generic drugs and from essential drug list. The study found that $48 \%$ (144) of prescription contain minimum one antibiotic. The most commonly prescribed antimicrobials were ciprofloxacin, metronidazole, amoxicillin, cefixime, and cefuroxime. Henceforth, researchers recommended that there is a serious requirement of effective EIs to promote and ensure rational prescribing and use of medicine [98]. One more study reported that no graduate pharmacist is employed in retail drugstores or public hospitals of Bangladesh except very few tertiary private hospitals. Although National Drug Policy 2005 of Bangladesh suggested that medicine dispensation and consumption should be under the supervision of qualified pharmacist in any health care settings. Furthermore, researchers demanded that pharmacists and proper pharmacy service can reduce medication errors and play vibrant role in promoting rational use of medicine [99]. Another study analyzed a total of 405 prescriptions of which $54 \%$ of child and $46 \%$ of adult prescriptions. This study detected that $54 \%$ of the prescription contain antimicrobials and concluded that irrational use of antimicrobials irrespective to the age of patients. As pediatric (66\%) and adult (40\%) both groups of were prescribed in very rate [100]. Henceforth, this also similarly contemplate that more than half of the expenditure for medicine were for antimicrobials [100-103]. In addition, another study reported that antibiotic was prescribed in $44 \%$ of audited prescription $(\mathrm{n}=1,496)$, more commonly for fever $(36-40 \%)$ and common cold (26-34\%) than for lower respiratory tract infection, including pneumonia (10-20\%). The research concluded that polypharmacy and overuse/misuse of drugs, particularly antibiotics, should be avert to circumvent microbial resistance and to promote and progress rational prescribing. Researchers also recommend for reinforcement of regulatory measures [104]. Another Bangladeshi study conducted in the rural health centers of Dhaka and Chittagong found that $55.57 \%$ of the physicians prescribe antibiotics in suspected infection, whereas only $33.46 \%$ prescribe antibiotics in after confirmatory laboratory investigation [105]. Researchers explained that from head to foot escalation microbial resistance in Bangladesh were probably linked with excessive use and misuse antimicrobials [106]. Henceforth, this team also demanded categorically operational administrative monitoring to prevent microbial resistance scenario $[105,106]$. One more study conducted in one of the prime teaching hospitals among inpatients quantified that 500 out of 1563 patients were prescribed antibiotics (38\%). Out of 500 prescriptions, 14\% (68) prescriptions were found irrational use antimicrobials. Researchers furthermore demanded that level-headedly little quantity of irrational use of antimicrobials. Authors also claimed that this might not be the actual 
depiction of the Bangladesh since their research was conducted in one of the best public teaching tertiary hospital situated in the capital city [107]. Another study detected that $64.28 \%$ isolates of Salmonella typhi were multidrug resistant. This study suggests that the clinical samples for culture and sensitivity were mostly resistant against nalidixic acid with all age groups of patients in three separate geographical areas with equal resistance outline. The high rate of multidrug resistance (MDR) is a real alarming and precarious issue regarding public health of Bangladesh [108]. A total of 233 Escherichia coli isolates obtained from 175 tap water samples were investigated and found that virtually $36 \%(n=84)$ were MDR and $26 \%(n=22)$ of these were positive for extended spectrum $\beta$-lactamase (ESBL) [108]. This is very alarming situation for country like Bangladesh as the domestic water supply is generally utilized as drinking water by common folks without any precautionary processing. Even though in Bangladesh, boiling of drinking water before consumption is repeatedly advised and in some occasion practiced by urban educated community. Hereafter, the incidence of MDR ESBL-producing pathogenic E. coli in domiciliary water supply in the capital city of Dhaka has imperative consequences for public health, especially for the city dwellers [109]. One more research conducted in Dhaka Medical College the oldest medical school in Bangladesh established during British Colonial period reported that $33 \%$ of interviewed doctors prefer to combination antimicrobials instead single agent. The choice of medicine depends on the availability of hospital supply (68\%), efficacy (61\%), safety (51\%), and cost (17\%). The far majority (93\%) prefer to prescribe in brand name [110]. Another research study revealed that most (50\%) common diagnosis to prescribe antimicrobial are fever, respiratory, and urinary tract infection. About $70 \%$ of physicians point out diagnostic ambiguity and advent of resistance were the foremost reasons for upsurge in antimicrobial prescribing. Nearly $51.9 \%$ of prescribers preached that doctors prescribe antimicrobial more than the authentic requisite. Around two-third of year- $V$ medical students responded appropriately on diverse concerns associated with antimicrobials and resistance. Antimicrobial and resistance received pintsize importance in pharmacology and microbiology written questions at both undergraduate $(0.7-16.1 \%)$ and postgraduate $(0.9-18.4 \%)$ level. Print $(0.02-2.0 \%)$ and electronic media $(0.0-0.6 \%)$ attaches insignificant importance on the AMDR. Antimicrobials and strategy to fight against microbial resistance were not at all talked in the official papers of health and allied science [111]. Another study long before commented that pharmacology teaching and assessment system in 5 year MBBS program neither reflect community need or course objectives [112]. Here it will be worth to mention that Bangladesh has an unique curriculum for throughout the country applicable for both public and private medical schools. In AMDR issue has so much it started appearing in several the daily newspaper. The Dhaka Tribune reported that "a lack of awareness among consumers and the callous attitude of a large section of physicians have turned many lifesaving antibiotic drugs into silent killers. Unlike in developed countries, Bangladesh does not have any strict regulations regarding OTC sales of antibiotic drugs, which, if in place, could have prevented people from purchasing antibiotics without prescriptions" [113]. Another newspaper reported that "the overuse and misuse of antibiotics are key factors contributing to antibiotic resistance, which eventually is causing a harmful impact on human health, health experts believed. Without doctor's prescription, no one should take antibiotics as its rampant use may increase chances of many diseases in the human body, they told the meet the press on improving awareness and understanding of antibiotic resistance in the capital" [114]. Another newspaper additionally reported that "excessive use of antibiotics continues unabated posing an increased threat to public life. Common people on several occasions, especially those unaware of the use of life-saving drugs, randomly take the medicine sometimes on their own without consulting qualified physicians and sometimes at the advice of physicians mostly having an unholy alliance with drug manufacturers. About $80 \%$ of antibiotics available on the market is consumed by livestock. The ingredients of the medicines applied to livestock usually find their way to humans through meat, potentially risking their immunity system. Besides, all this may give rise to drug-resistant microbes, severely weakening the entire human fight against various fatal infections. In short, if the misuse of antibiotics is continued for long time, it may send back the humankind to the ages when village after village in different countries became depopulated due to fatal diseases caused by various microbes" [115]. The one of most powerful English newspaper of Bangladesh reported that antibiotic misuse reduces the sensitivity of the drugs against various diseases leaving people more vulnerable. Studies show that antibiotics such as cefpodoxime and ceftriaxone are used widely for treating Accident Research Institute (ARI), as azithromycin, amoxicillin, and ampicillin do not work effectively against ARI in Bangladesh. Similarly, the effectiveness of ciprofloxacin against cholera has been reduced to $44 \%$ in 2009 from $93 \%$ in 1993 . Stressing the need for the rational use of antibiotics, the experts said that forming national alliances and comprehensive strategy are important to stop microbial resistance" [116]. In addition, the same newspaper reported recently that "overusing antibiotics for illnesses that do not require such medication has been on the increase in Bangladesh, indicates recent International Centre for Diarrhoeal Disease Research, Bangladesh, B studies. A recent study that examined the use of antibiotics by children under 2 years of age in Dhaka has shown that each child has taken over 10 antibiotic courses per year on average - an alarmingly high rate compared to global standards" [117].

\section{CONCLUSION}

Irrational and excessive of antimicrobials exits all these 10 developing countries. The resistance pattern is quite alarming as there are often observed multiple drug-resistant microbes. Researchers from India highly recommended that "patients, as well as health care professionals, have a major role to play in attaining rational antibiotic use. Antibiotic awareness campaigns and patient counseling should promote specific messages to public members from the high-risk groups, to fill up the knowledge and attitude gaps" [118]. Henceforth, it was revealed that "education of the prescriber is the cornerstone of any successful antibiotic stewardship program, and teaching of guidelines and clinical pathways will aid in improving antimicrobial prescribing behavior to a large extent" [119]. Thereafter, the current review equally supports all these countries research recommendation that EIs as a form continued medical education not only for graduate doctors but also for all stakeholders to prevent and protect from the threat of most powerful and intelligent microbes and to safeguard our community. Medical doctors remain in the central point for all the shareholders and partner of health, especially of prescribing and utilization of medicine. Afterward, it will be much better to produce highly professional and committed medical doctor to start EIs in early days of the medical school [31-33, 120-124]. Nonetheless, medical educationist must need remember not to increase stress among the undergraduate medical students as there are already of much academic load and stress [125-132]. It is as well recommended to promote rigorous and stern regulatory measures and long-term policy for overuse and irrational use of antimicrobials.

\section{REFERENCES}

1. Kumar D, Singh AK, Ali MR, Chander Y. Antimicrobial susceptibility profile of extended spectrum B-lactamase (ESBL) producing Escherichia coli from various clinical samples. Infect Dis (Auckl) 2014;7:1-8.

2. Kumar M, Chaudhary S, Makkar DK, Garg N, Chugh S. Comparative antimicrobial efficacy evaluation of a new product elores against meropenem on gram-negative isolates. Asian J Pharm Clin Res $2015 ; 8(4): 251-4$

3. Levy SB. The challenge of antibiotic resistance. Sci Am 1998;278(3):46-53.

4. World Health Organization (WHO). The Evolving Threat of Antimicrobial Resistance Options for Action. Geneva, Switzerland: WHO Press, World Health Organization; 2012. Available from: http:// www.apps.who.int/iris/bitstream/10665/44812/1/9789241503181_ eng.pdf. [Last accessed on $2017 \mathrm{Apr}$ 07].

5. Levy SB. The 2000 Garrod lecture. Factors impacting on the problem 
of antibiotic resistance. J Antimicrob Chemother 2002;49(1):25-30.

6. Thriemer K, Katuala Y, Batoko B, Alworonga JP, Devlieger H, Van Geet C, et al. Antibiotic prescribing in DR Congo: A knowledge, attitude and practice survey among medical doctors and students. PLoS One 2013;8(2):e55495.

7. Boucher HW, Talbot GH, Bradley JS, Edwards JE, Gilbert D, Rice LB, et al. Bad bugs, no drugs: No ESKAPE! An update from the Infectious Diseases Society of America. Clin Infect Dis 2009;48(1):1-12.

8. Bradley JS, Guidos R, Baragona S, Bartlett JG, Rubinstein E, Zhanel GG, et al. Anti-infective research and development - Problems, challenges, and solutions. Lancet Infect Dis 2007;7(1):68-78.

9. Cars O, Hogberg LD, Murray M, Nordberg O, Sivaraman S, Lundborg CS, et al. Meeting the challenge of antibiotic resistance. BMJ 2008;337:a1438.

10. IDSA. IDSA Report: Bad Bugs, No Drugs: As Antibiotic Discovery Stagnates, A Public Health Crisis Brews. Alexandria (VA), USA: Infectious Diseases Society of America; 2004. Available from: https:// www.idsociety.org/uploadedFiles/IDSA/Policy_and_Advocacy/ Current_Topics_and_Issues/Advancing_Product_Research and Development/Bad Bugs No Drugs/Statements/As\%20

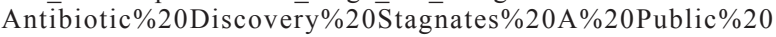
Health\%20Crisis\%20Brews.pdf. [Last accessed on 2017 Apr 13].

11. Nathan C. Antibiotics at the crossroads. Nature 2004:431:899-902.

12. Nathan C. Cooperative development of antimicrobials: Looking back to look ahead. Nat Rev Microbiol 2015;13(10):651-7.

13. Norrby SR, Nord CE, Finch R; European Society of Clinical Microbiology and Infectious Diseases. Lack of development of new antimicrobial drugs: A potential serious threat to public health. Lancet Infect Dis 2005;5(2):115-9.

14. Spellberg B, Powers JH, Brass EP, Miller LG, Edwards JE Jr. Trends in antimicrobial drug development: Implications for the future. Clin Infect Dis 2004;38(9):1279-86.

15. Ventola CL. The antibiotic resistance crisis: Part 1: Causes and threats. P T 2015;40(4):277-83

16. Nathan C, Cars O. Antibiotic resistance - Problems, progress, and prospects. N Engl J Med 2014;371(19):1761-3.

17. Centres for Disease Control and Prevention, Office of Infectious Disease. Antibiotic resistance threats in the United States, 2013. April; 2013. Available from: https://www.cdc.gov/drugresistance/pdf/ ar-threats-2013-508.pdf. [Last accessed on 2017 Apr 14].

18. Spellberg B, Gilbert DN. The future of antibiotics and resistance: A tribute to a career of leadership by John Bartlett. Clin Infect Dis 2014;59 Suppl 2:S71-5

19. Michael CA, Dominey-Howes D, Labbate M. The antibiotic resistance crisis: Causes, consequences, and management. Front Public Health 2014;2:145.

20. Read AF, Woods RJ. Antibiotic resistance management. Evol Med Public Health 2014;2014:147.

21. The antibiotic alarm. Nature 2013;495(1):141

22. Luyt CE, Bréchot N, Trouillet JL, Chastre J. Antibiotic stewardship in the intensive care unit. Crit Care 2014;18(5):480.

23. Okeke I. Poverty and root causes of resistance in developing countries. In: Sosa AJ, Byarugaba DK, Amabile-Cuevas CF, Hsueh PR, Kariuki S, Okeke IN, editors. Antimicrobial Resistance in Developing Countries. $1^{\text {st }}$ ed. New York: Springer; 2001. p. 27-36. Available from: http://www.emerald.tufts.edu/med/apua/about us/ publications 21 3125925763.pdf. [Last accessed on 2017 Apr 14]

24. Bergmans DC, Bonten MJ, Gaillard CA, van Tiel FH, van der Geest S, de Leeuw PW, et al. Indications for antibiotic use in ICU patients: A oneyear prospective surveillance. J Antimicrob Chemother 1997;39:527-35.

25. Roberts JA, Paul SK, Akova M, Bassetti M, De Waele JJ, Dimopoulos G, et al. DALI: Defining antibiotic levels in intensive care unit patients: Are current beta-lactam antibiotic doses sufficient for critically ill patients? Clin Infect Dis 2014;58(8):1072-83.

26. Kollef MH. Optimizing antibiotic therapy in the intensive care unit setting. Crit Care 2001;5(4):189-95.

27. Kollef MH, Fraser VJ. Antibiotic resistance in the intensive care unit. Ann Intern Med 2001;134(4):298-314.

28. Patel P, Shah J, Nyati P, Nyati S. A survey on knowledge and attitude of rational use of antibiotics on predesigned proforma among interns and $1^{\text {st }}$ year postgraduate students. Int J Pharm Sci Res 2016;7(8):350-6.

29. Velo GP, Minuz P. Medication errors: Prescribing faults and prescription errors. Br J Clin Pharmacol 2009;67(6):624-8

30. Yousefi N, Majdzadeh R, Valadkhani M, Nedjat $S$, Mohammadi H. Reasons for physicians' tendency to irrational prescription of corticosteroids. Iran Red Crescent Med J 2012;14(11):713-8
31. Hoque R, Mostafa A, Haque M. Insight of medical students of clinical years to antimicrobials prescribing and resistance in private medical school, Chittagong, Bangladesh. J Young Pharm 2016;8(4):447-55.

32. Haque M, Rahman NI, Zulkifli Z, Ismail S. Antibiotic prescribing and resistance: Knowledge level of medical students of clinical years of University Sultan Zainal Abidin, Malaysia. Ther Clin Risk Manag 2016;12:413-26.

33. Hoque R, Mostafa A, Haque M. Intern doctors' views on the current and future antibiotic resistance situation of Chattagram Maa $\mathrm{O}$ Shishu Hospital Medical College, Bangladesh. Ther Clin Risk Manag 2015;11:1177-85.

34. Rothwell C, Burford B, Morrison J, Morrow G, Allen M, Davies C, et al. Junior doctors prescribing: Enhancing their learning in practice. Br J Clin Pharmacol 2012;73(2):194-202.

35. De Vries TP, Henning RH, Hogerzeil HV, Fresle DA. Guide to Good Prescribing: A Practical Manual, (WHO DAP/94.11). Geneva: WHO; 1994. Available from: http://www.apps.who.int/medicinedocs/pdf/ whozip23e/whozip23e.pdf. [Last accessed on 2017 Apr 14]

36. Khilnani G. The concept of personal drugs in the undergraduate pharmacology practical curriculum. Indian J Pharmacol 2008;40(3):131-2.

37. Parmar DM, Jadav SP. The concept of personal drugs in the undergraduate pharmacology practical curriculum. Indian J Pharmacol 2007;39(3):165-7.

38. Rai J. Recommendations for undergraduate pharmacology practical curriculum (for attention of MCI). JK Pract 2006;13(3):175-6.

39. Singh NR. P-drug concept and the undergraduate teaching. Indian J Pharmacol 2008;40(6):285.

40. Pattnaik KP, Mohapatra S, Mohanty M, Mohapatra BN, Patel D, Mukherji D. Clinical orientation of undergraduate pharmacology practicals: An intervention study. Indian J Pharmacol 2006;38(3):200-2.

41. Baadani AM, Baig K, Alfahad WA, Aldalbahi S, Omrani AS. Physicians' knowledge, perceptions, and attitudes toward antimicrobial prescribing in Riyadh, Saudi Arabia. Saudi Med J 2015;36(5):613-9.

42. Alothman A, Algwizani A, Alsulaiman M, Alalwan A, Binsalih S, Bosaeed M. Knowledge and attitude of physicians toward prescribing antibiotics and the risk of resistance in two reference hospitals. Infect Dis (Auckl) 2016;9:33-8.

43. Al-Harthi SE, Khan LM, Osman AM, Alim MA, Saadah OI, Almohammadi AA, et al. Perceptions and knowledge regarding antimicrobial stewardship among clinicians in Jeddah, Saudi Arabia. Saudi Med J 2015;36(7):813-20.

44. Ghosh A, Deb T, Ghosh S. Knowledge, attitudes and practice survey about antimicrobial resistance and prescribing among physicians in a tertiary care teaching hospital in Eastern India. Int $\mathrm{J}$ Basic Clin Pharmacol 2016;5(1):180-7.

45. Sampath S, Venoukichenane V. Knowledge, attitude and practice of antibiotics usage among health care personnel in a tertiary care hospital. Sch J Appl Med Sci 2016;4(9B):3294-8.

46. Padmanabha TS, Nandini T, Manu G, Madhav KS, Ravi SM. Knowledge, attitude and practices of antibiotic usage among the medical undergraduates of a tertiary care teaching hospital: An observational cross-sectional study. Int $\mathrm{J}$ Basic Clin Pharmacol 2016;5(6):2432-7.

47. Hui L, Li XS, Zeng XJ, Dai YH, Foy HM. Patterns and determinants of use of antibiotics for acute respiratory tract infection in children in China. Pediatr Infect Dis J 1997;16(6):560-4.

48. Dong H, Bogg L, Rehnberg C, Diwan V. Association between health insurance and antibiotics prescribing in four counties in rural China. Health Policy 1999;48(1):29-45.

49. Dong H, Bogg L, Rehnberg C, Diwan V. Health financing policies. Providers' opinions and prescribing behaviour in rural China. Int J Technol Assess Health Care 1999;15(4):686-98.

50. Reynolds L, McKee M. Factors influencing antibiotic prescribing in China: An exploratory analysis. Health Policy 2009;90(1):32-6.

51. Bai Y, Wang S, Yin X, Bai J, Gong Y, Lu Z. Factors associated with doctors' knowledge on antibiotic use in China. Sci Rep 2016;6:23429.

52. Hassali MA Kamil TK, Md Yusof FA, Alrasheedy AA, Yusoff ZM, Saleem F, et al. General practitioners' knowledge, attitude and prescribing of antibiotics for upper respiratory tract infections in Selangor, Malaysia: Findings and implications. Expert Rev Anti Infect Ther 2015;13(4):511-20.

53. Kho BP, Ong CM, Tan FT, Wee CY. Antibiotic prescribing for upper respiratory tract infections in Sarawak district hospitals. Med J Malaysia 2013;68:136-40.

54. Paraidathathu T, Li CY, Siang CS. Treatment of symptoms of common 
cold by general practitioners in Malaysia. Int $\mathrm{J}$ Pharm Pharm Sci 2012;4(4):479-81.

55. Tillekeratne LG, Bodinayake CK, Dabrera T, Nagahawatte A, Arachchi WK, Sooriyaarachchi A, et al. Antibiotic overuse for acute respiratory tract infections in Sri Lanka: A qualitative study of outpatients and their physicians. BMC Fam Pract 2017;18(1):37.

56. Mostafavi N, Rashidian A, Karimi-Shahanjarini A, Khosravi A, Kelishadi R. The rate of antibiotic utilization in Iranian under 5-year-old children with acute respiratory tract illness: A nationwide community-based study. J Res Med Sci 2015;20(5):429-33.

57. Khodabakhshi B, Moradi A, Bijani E, Mansouri S, Besharat S, Besharat M. Pattern of antibiotics prescription in a referral academic hospital, Northeast of Iran. J Glob Infect Dis 2014;6(1):42-3.

58. Adebayo ET, Hussain NA. Pattern of prescription drug use in Nigerian army hospitals. Ann Afr Med 2010;9(3):152-8.

59. Ebrahimzadeh MA, Shokrzadeh M, Ramezani A. Utilization pattern of antibiotics in different wards of specialized Sari Emam University Hospital in Iran. Pak J Biol Sci 2008;11(2):275-9.

60. Hutchinson JM, Patrick DM, Marra F, Ng H, Bowie WR, Heule L, et al. Measurement of antibiotic consumption: A practical guide to the use of the Anatomical Thgerapeutic Chemical classification and Definied Daily Dose system methodology in Canada. Can J Infect Dis 2004;15(1):29-35.

61. Salam A, Haque M, Islam MZ, Rahman NI, Helai AM, Muda TF, et al. Addressing rational prescribers through the pharmacology and therapeutics course work of MBBS syllabus in Bangladesh. Int Res J Pharm 2013;4(7):60-3

62. Miyawaki K, Miwa Y, Tomono K, Kurokawa N. Impact of antimicrobial stewardship by infection control team in a Japanese teaching hospital. Yakugaku Zasshi 2010;130(8):1105-11.

63. Habibzadeh F. Use and misuse of antibiotics in the Middle East. Lancet 2013;382:1

64. Hatam N, Askarian M, Moravveji AR, Assadian O. Economic burden of inappropriate antibiotic use for prophylactic purpose in Shiraz, Iran. Iran Red Crescent Med J 2011;13(4):234-8.

65. Adeli O, Moghaddam NM, Farahani RH, Jame SZ. Antibiotics use patterns in intensive care units of five hospitals in Tehran during 2011-2012. J Arch Mil Med 2015;3(3):e27862.

66. Askarian M, Reza Moravveji A, Assadian O. Prescription of prophylactic antibiotics for neurosurgical procedures in teaching hospitals in Iran. Am J Infect Control 2007;35(4):260-2.

67. Moradi J, Hashemi FB, Bahador A. Antibiotic resistance of Acinetobacter baumannii in Iran: A systemic review of the published literature. Osong Public Health Res Perspect 2015;6(2):79-86.

68. Fredrickson T. Overuse of Antibiotics Killing Thais at High Rate. Bangkok Post; 2015. Available from: http://www.bangkokpost.com/ learning/learning-news/779433/overuse-of-antibiotics-killing-thaisat-high-rate. [Last accessed on 2017 Apr 22].

69. Ayuthya SK, Matangkasombut OP, Sirinavin S, Malathum K, Sathapatayavongs B. Utilization of restricted antibiotics in a university hospital in Thailand. Southeast Asian J Trop Med Public Health 2003;34(1):179-86.

70. Aswapokee N, Vaithayapichet S, Heller RF. Pattern of antibiotic use in medical wards of a university hospital, Bangkok, Thailand. Rev Infect Dis 1990;12(1):136-41.

71. Apisarnthanarak A, Danchaivijitr S, Khawcharoenporn T, Limsrivilai J, Warachan B, Bailey $\mathrm{TC}$, et al. Effectiveness of education and an antibiotic-control program in a tertiary care hospital in Thailand. Clin Infect Dis 2006;42(6):768-75.

72. Belongia EA, Schwartz B. Strategies for promoting judicious use of antibiotics by doctors and patients. BMJ 1998;317(7159):668-71.

73. Apisarnthanarak A, Danchaivijitr S, Bailey TC, Fraser VJ. Inappropriate antibiotic use in a tertiary care center in Thailand: An incidence study and review of experience in Thailand. Infect Control Hosp Epidemiol 2006;27(4):416-20.

74. Bhavnani D, Phatinawin L, Chantra S, Olsen SJ, Simmerman JM. The influence of rapid influenza diagnostic testing on antibiotic prescribing patterns in rural Thailand. Int J Infect Dis 2007;11(4):355-9.

75. O'Brien TF. Resistance of bacteria to antibacterial agents: Report of Task Force 2. Rev Infect Dis 1987;9 Suppl 3:S244-60.

76. Liss RH, Batchelor FR. Economic evaluations of antibiotic use and resistance - A perspective: Report of Task Force 6. Rev Infect Dis 1987;9 Suppl 3:S297-312.

77. Thomas $\mathbf{J} 3^{\text {rd }}$. National survey of hospital policies on pharmaceutical sales representatives' activities. Am J Hosp Pharm 1987;44(6):1334-40.

78. Velmonte MA. Surveillance of antibiotic susceptibility at the Philippine general hospital. Acta Med Philipp 1985;21(4):126-31.
79. Emmanuel ER. Inappropriate antibiotic use in the Philippines. Phil J Microbiol Infect Dis 1997;26(2):77-87.

80. Samaniego TS. Improper Use of Antibiotics May Lead to Evolution of Infectious Superbugs. Philippine Daily Inquirer; 2011. Available from: http://www.business.inquirer.net/34317/improper-use-ofantibiotics-may-lead-to-evolution-of-infectious-superbugs. [Last accessed on 2017 Apr 23].

81. Lansang MA, Lucas-Aquino R, Tupasi TE, Mina VS, Salazar LS, Juban N, et al. Purchase of antibiotics without prescription in Manila, the Philippines. Inappropriate choices and doses. J Clin Epidemiol 1990;43(1):61-7.

82. Hardon AP. The use of modern pharmaceuticals in a Filipino village: Doctors' prescription and self medication. Soc Sci Med 1987;25(3):277-92.

83. Morgan DJ, Okeke IN, Laxminarayan R, Perencevich EN, Weisenberg S. Non-prescription antimicrobial use worldwide: A systematic review. Lancet Infect Dis 2011;11(9):692-701.

84. Alam K, Mishra P, Prabhu M, Shankar PR, Palaian S, Bhandari RB, et al. A study on rational drug prescribing and dispensing in outpatients in a tertiary care teaching hospital of Western Nepal. Kathmandu Univ Med J (KUMJ) 2006;4(4):436-43

85. Upadhyay DK, Palaian S, Shankar PR, Mishra P. Rational drug prescribing and dispensing in tertiary care teaching hospital of Western Nepal. J Inst Med 2008;30(2):33-8.

86. Remesh A, Gayathri AM, Singh R, Retnavally KG. The knowledge, attitude and the perception of prescribers on the rational use of antibiotics and the need for an antibiotic policy-a cross sectional survey in a tertiary care hospital. J Clin Diagn Res 2013;7(4):675-9.

87. Dahal P, Bhattarai B, Adhikari D, Shrestha R, Baral SR, Shrestha N. Drug use pattern in primary health care facilities of Kaski district, Western Nepal. Sunsari Tech Coll J 2012;1(1):1-8.

88. World Health Organisation (WHO). Promoting Rational Use of Medicine Core Components. WHO Policy Prospectives on Medicine, (WHO/EDL/2002.3). Geneva. Available from: http://www.archives. who.int/tbs/rational/h3011e.pdf. [Last accessed on 2017 Apr 24].

89. Ghimire S, Nepal S, Bhandari S, Nepal P, Palaian S. A prospective surveillance of drug prescribing and dispensing in a teaching hospital in Western Nepal. J Pak Med Assoc 2009;59(10):726-31.

90. Chapagain K, Pokharel R, Paranjape BD. Evaluation of prescription pattern and rational prescribing in Eastern Nepal. J Nobel Med Coll 2016;5(1):32-6.

91. Shankar RP, Partha P, Shenoy NK, Easow JM, Brahmadathan KN. Prescribing patterns of antibiotics and sensitivity patterns of common microorganisms in the Internal Medicine ward of a teaching hospital in Western Nepal: A prospective study. Ann Clin Microbiol Antimicrob 2003;2:7

92. Biswas M, Roy DN, Tajmim A, Rajib SS, Hossain M, Farzana F, et al. Prescription antibiotics for outpatients in Bangladesh: A crosssectional health survey conducted in three cities. Ann Clin Microbiol Antimicrob 2014;13:15.

93. Faiz MA, Basher A. Antimicrobial resistance: Bangladesh experience. Reg Health Forum 2011;15(1):1-8.

94. Amin MN. Use and misuse of antibiotics. Ibrahim Cardiac Med J 2001;1(2):7-9.

95. Biswas M, Roy DN, Rahman MM, Islam M, Parvez GM, Haque MU, et al. Doctor's prescribing trends of antibiotics for out patients in Bangladesh: A cross-sectional health survey conducted in three districts. Int J Pharm Sci Res 2015;6(2):669-75.

96. Chang SC, Chang HJ, Lai MS. Antibiotic usage in primary care units in Taiwan. Int J Antimicrob Agents 1999;11(1):23-30.

97. Sutradhar KB, Saha A, Huda NH, Uddin R. Irrational use of antibiotics and antibiotic resistance in Southern rural Bangladesh: Perspectives from both the physicians and patients. Annu Res Rev Biol 2014;4(9):1421-30.

98. Alam MM, Parveen F, Ara F, Iqbal MJ, Saha RR. Prescribing trends in the out-patient department in a tertiary hospital in Bangladesh. Bangladesh Med J 2011;40(2):8-12

99. Shill MC, Das AK. Medication practices in Bangladesh - Roles of pharmacists at current circumstances. Int J Pharm Pharm Sci 2011;3 Suppl 4:5-8.

100. Datta SK, Paul TR, Monwar M, Khatun A, Islam MR, Ali MA, et al. Patterns of prescription and antibiotic use among outpatients in a tertiary care teaching hospital of Bangladesh. Int J Pharm Pharm Sci 2016;8(11):60-3

101. Hossain MM, Glass RI, Khan MR. Antibiotic use in a rural community in Bangladesh. Int J Epidemiol 1982;11(4):402-5. 
102. Gustafsson LL, Wide K. Marketing of obsolete antibiotics in Central America. Lancet 1981;1(8210):31-3.

103. Ratanawijitasin S. Drug users in Thailand: Identifying problems and developing strategies for rational use of drugs. INRUD News 1996;6:21.

104. Ahmed SM, Islam QS. Availability and rational use of drugs in primary healthcare facilities following the national drug policy of 1982: Is Bangladesh on right track? J Health Popul Nutr 2012;30(1):99-108.

105. Hasan SM, Hossain MM, Akter R, Karim SM, Haque S, Kamaluddin M, et al. Pattern of antibiotics use at the primary health care level of Bangladesh: Survey report-1. Stamford J Pharm Sci 2009;2(1):1-7.

106. Guyon AB, Barman A, Ahmed JU, Ahmed AU, Alam MS. A baseline survey on use of drugs at the primary health care level in Bangladesh. Bull World Health Organ 1994;72(2):265-71.

107. Begum T, Khan MI, Kawser S, Huq ME, Majid N, Akhter A. An audit of rational use of antibiotics in a tertiary hospital. Delta Med Coll J 2014;2(2):64-7.

108. Mannan A, Shohel M, Rajia S, Mahmud NU, Kabir S, Hasan I. A cross sectional study on antibiotic resistance pattern of Salmonella typhi clinical isolates from Bangladesh. Asian Pac J Trop Biomed 2014;4(4):306-11.

109. Talukdar PK, Rahman M, Rahman M, Nabi A, Islam Z, Hoque MM, et al. Antimicrobial resistance, virulence factors and genetic diversity of Escherichia coli isolates from household water supply in Dhaka, Bangladesh. PLoS One 2013;8(4):e61090.

110. Karim A, Haque M. Study of the extent and pattern of the use of analgesic and antibiotics during operation in the surgical and gynaecological units of a teaching hospitals. J Dhaka Med Coll 1995;4(2):85-8.

111. Rahman MS, Huda S. Antimicrobial resistance and related issues: An overview of Bangladesh situation. Bangladesh J Pharmacol 2014;9(2):218-24.

112. Karim A, Haque M. Assessment system in pharmacology-does it reflect educational objectives and community health needs? Bangladesh J Physiol Pharmacol 1996;12(2):65-7.

113. Uzzal M. Overuse Turns Antibiotics into Silent Killers. Dhaka Tribune; 2013. Available from: http://www.archive.dhakatribune. com/wellness/2013/sep/19/overdose-turns-antibiotics-silent-killers. [Last accessed on 2017 Apr 28].

114. BSS. Misuse of Antibiotics Causes Harmful Impact, Say Experts. The Independent; 2016. Available from: http://www.theindependentbd. com/arcprint/details/69185/2016-11-21. [Last accessed on 2017 Apr 28].

115. New Age Opinion. No More Misuse of Antibiotics. New Age; 2016. Available from: http://www.newagebd.net/article/3088/no-moremisuse-of-antibiotics. [Last accessed on 2017 Apr 28].

116. Staff Correspondent. Antibiotic Misuse Raises Risk. The Daily Star; 2011. Available from: http://www.thedailystar.net/newsdetail-180953. [Last accessed on 2017 Apr 28].

117. Nabil M. The Malaise of Antibiotic Overuse. The Daily Star; 2016. Available from: http://www.thedailystar.net/opinion/society/themalaise-antibiotic-overuse-1390387. [Last accessed on 2017 Apr 28].

118. Chandrakanth P, Saleem TS, Reddy MM, Gopinath C, Rao MM. Assessment of public knowledge and attitude regarding antibiotic use in a tertiary care hospital. Asian J Pharm Clin Res 2016;9(1):118-22.
119. Singh AP, Gupta U, Das S. Monitor the use of antibiotics in intensive care units with special focus on restricted antibiotics in tertiary care hospital of India. Asian J Pharm Clin Res 2016;9(1):256-9.

120. Salam A, Yousuf R, Islam MZ, Yesmin F, Helali AM, Alattraqchi AG, et al. Professionalism of future medical professionals in Universiti Sultan Zainal Abidin, Malaysia. Bangladesh J Pharmacol 2013;8(2):124-30.

121. Salam A, Haque M, Islam MZ, Helali AM, Yousuf R, Yesmin F, et al. Comparative study of professionalism of future medical professionals among three private medical colleges of Bangladesh. Asian J Pharm Clin Res 2013;6(3):170-9.

122. Salam A, Haque M, Helali AM, Islam MZ, Mohsena MA, Rahman ZA, et al. Comparative study on professionalism of forthcoming medical doctors between two private medical colleges in Savar, Bangladesh. Int J Pharm Pharm Sci 2013;5(3):659-65.

123. Islam MZ, Salam A, Helali AM, Rahman Z, Dali WP, Ismail S, et al. Comparative study of professionalism of future medical doctors between Malaysia and Bangladesh. J Appl Pharm Sci 2014;4(4):66-71.

124. Haque M, Zulkifli Z, Haque SZ, Kamal ZM, Salam A, Bhagat V, et al. Professionalism perspectives among medical students of a novel medical graduate school in Malaysia. Adv Med Educ Pract 2016;7:407-22

125. Eva EO, Islam MZ, Mosaddek AS, Rahman MF, Rozario RJ, Iftekhar AF, et al. Prevalence of stress among medical students: A comparative study between public and private medical schools in Bangladesh. BMC Res Notes 2015;8:327.

126. Salam A, Yousuf R, Bakar SM, Haque M. Stress among medical students in Malaysia: A systematic review of literatures. Int Med J 2013;20(6):649-55.

127. Rahman NI, Ismail SB, Seman TN, Rosli NF, Jusoh SA, Dali WP, et al. Stress among preclinical medical students of University Sultan Zainal Abidin. J Appl Pharm Sci 2013;3(11):76-81.

128. Rahman NI, Ismail SB, Ali RM, Alattraqchi AG, Dali WP, Umar BU, et al. Stress among first batch of MBBS students of faculty of medicine and health sciences, Universiti Sultan Zainal Abidin, Malaysia: When final professional examination is knocking the door. Int Med J 2015;22(4):254-9.

129. Ismail S, Rahman NI, Mohamad N, Jusoh NM, Hood AI, Arif LA, et al. Preference of teaching and learning methods in a new medical school of Malaysia. J Appl Pharm Sci 2014;4(2):48-55.

130. Rahman NI, Aziz AA, Zulkifli Z, Haj MA, Mohd Nasir FH, Pergalathan $\mathrm{S}$, et al. Perceptions of students in different phases of medical education of the educational environment: Universiti Sultan Zainal Abidin. Adv Med Educ Pract 2015;6:211-22.

131. Mohsena M, Debsarma S, Haque M. Determining the quality of educational climate in a private medical college in Bangladesh via the "dundee ready education environment measure" instrument. J Young Pharm 2016;8(3):266-74

132. Haque M, Zulkifli Z, Nasir FH, Majumder MA, Yusoff MS, Mostafa A, et al. Perception of tomorrow's health-care connoisseur and frontrunners of their educational environment utilizing DREEM inventory in Bahasa Melayu. Version, the native language of Malaysia. AMJ 2017;10(5):361-72. 